\title{
THE BEHAVIOR OF SUSPENDED SOLID PARTICLES AND LIQUID IN BUBBLE COLUMNS*
}

\author{
YASUO KATO**, AKIO NISHIWAKI**, TAKASHI FUKUDA*** AND \\ SHIGENOBU TANAKA*** \\ Department of Applied Chemistry, Kyushu University, Fukuoka, Japan** \\ The Government Industrial Development Laboratory, Hokkaido, Sapporo, \\ Japan***
}

\begin{abstract}
The longitudinal concentration distribution of solid particles and liquid mixing in 6.6, 12.2 and $21.4 \mathrm{~cm}$ i.d. bubble columns were measured and were analyzed by using diffusion model. The longitudinal dispersion coefficient of solid particles and liquid based on actual mean slurry velocity, the mean settling velocity of solid particles, and the concentration of solid particles at the top of the column, respectively, were correlated with dimensionless groups. From these correlations empirical equations were obtained. The values of concentration of solid particles calculated from the empirical equations agreed with the observed values within $\pm 20 \%$.
\end{abstract}

\section{Introduction}

With the improved design of bubble columns containing suspended solid particles, a more satisfactory elucidation of the relation between the behavior of suspended solid particles and liquid in the column and operating conditions is necessary.

Suganuma et al. ${ }^{7}$ ) measured the longitudinal concentration distribution of solid particles in batch and continuous operations for bubble columns of 6 , 11.8 and $20.1 \mathrm{~cm}$ in diameter, and presented an empirical equation for the range where a linear relationship between the logarithmic concentration of solid particles and the axial height from the bottom of the column holds approximately. Goto et al..$^{4}$ and Farkas et al. ${ }^{3}$ ) investigated the concentration distribution of solid particles in batch operations for 7.75, 20 and $90 \mathrm{~cm}$ columns and for a $3.81 \mathrm{~cm}$ column, respectively. $\mathrm{Cova}^{2)}$ investigated 4.57, 6.35 and 44.7 $\mathrm{cm}$ columns in cocurrent and countercurrent flow. He reported that the concentration distribution of solid particles in these columns was equal to that calculated by a sedimentation diffusion model, on the assumption that the dispersion coefficient of solid particles was the same as that of liquid and that the settling velocity of solid particles was equal to the terminal velocity of a single particle in stagnant liquid. Imafuku et al.5) measured the concentration distribution of solid particles in batch operations for 5, 10 and $20 \mathrm{~cm}$ columns and in continuous operations for a $10 \mathrm{~cm}$ column.

* Received on April 5, 1971

Presented at Hokkaido Meeting (at Sapporo, August 1968) and the 35th Annual Meeting (at Tokyo, April 1970) of the Society of Chemical Engineers, Japan
They reported that from the analysis of their data the dispersion coefficient of solid particles had the same value as that of liquid in a gas-liquid system, and they also presented an empirical equation for the settling velocity of solid particles in a bubble column as a function of the terminal velocity of a single particle in stagnant liquid and a voidage function. According to $\mathrm{Cova}^{2)}$ and Imafuku et al.5), in cocurrent flow the concentration of solid particles at the top of the column is equal to that in effluent (or feed) slurry, but the former is higher than the latter according to Suganuma et al. ${ }^{8)}$.

Although there are several papers as mentioned above, experimental data and their arrangement have not been sufficient to obtain an improved design of bubble columns containing suspended solid particles. Therefore, in this study the longitudinal concentration distribution of solid particles and liquid mixing in 6.6, 12.2 and $21.4 \mathrm{~cm}$ bubble columns were measured; and the correlation between operating conditions and the longitudinal dispersion coefficient of solid particles, the settling velocity of solid particles, the ratio of the concentration of solid particles at the top of the column to that in effluent (or feed) slurry, and the longitudinal dispersion coefficient of liquid are discussed.

\section{Experimental Apparatus and Procedures}

A schematic diagram of the experimental apparatus is shown in Fig. 1. Bubble columns of 6.6, 12.2 and $21.4 \mathrm{~cm}$ in diameter, having heights of 201, 196 and $405 \mathrm{~cm}$, respectively, were used. The column, made of transparent acrylic plastic, was equipped with a gas distributor of the same diameter as that of the column. As gas distributors, three perforated plates were used 


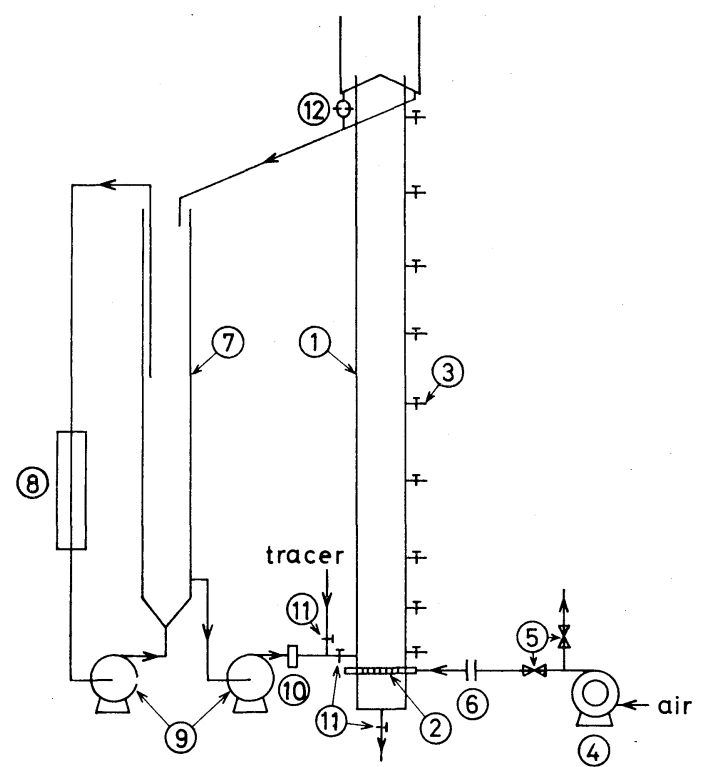

(1) bubble column (2) gas distributor (3) sampling tap (4) air compressor (5) valve (6) orifice meter

(7) slurry column (8) thermostatic device

(9) slurry pump (10) Venturi meter (11) cock

(12) electrical conductivity cell

Fig. 1 Experimental apparatus

(that for the $6.6 \mathrm{~cm}$ column had 31 holes of $0.1 \mathrm{~cm}$, that for the $12.2 \mathrm{~cm}$ column had 97 holes of $0.1 \mathrm{~cm}$ and was covered with 200-mesh wire gauze, and that for the $21.4 \mathrm{~cm}$ column had 336 holes of $0.1 \mathrm{~cm}$ and was covered with 250-mesh wire gauze). The system in the column consisted of air, water and glass spheres. Five size ranges of glass spheres with a density of $2.52 \mathrm{~g} /$ $\mathrm{cm}^{3}$ were used: $63 \sim 88,88 \sim 105,105 \sim 125,125 \sim 149$ and $149 \sim 177 \mu$ in diameter.

The longitudinal concentration distribution of solid particles was measured in batch and continuous (cocurrent) operation for slurry flow. In the batch operation, air from a compressor was first measured by an orifice flowmeter and blown into the column through the gas distributor. A definite amount of tap-water and solid particles was then fed into the column. After a steady concentration distribution of solid particles was established, samples of slurry were withdrawn through sampling taps into measuring cylinders. In the continuous operation, air was blown into the column through the orifice flowmeter and the gas distributor. The slurry from the slurry column was measured by a Venturi flowmeter and introduced into the bubble column at a point above the gas distributor. Then the slurry was allowed to flow upwards cocurrently with the air and to overflow from the top of the column into the slurry column. After the solid particle concentration in the overflowing slurry from the top of the column and the concentration distribution of solid particles in the column became steady, samples were taken from the sampling taps into measuring cylinders. The volume of each sample was measured and then solid particles
Table 1 Experimental conditions for continuous operations

\begin{tabular}{|c|c|c|c|c|c|c|}
\hline $\begin{array}{c}D_{\mathrm{T}} \\
{[\mathrm{cm}]}\end{array}$ & $\begin{array}{c}L \\
{[\mathrm{~cm}]}\end{array}$ & $\begin{array}{c}t \\
{\left[{ }^{\circ} \mathrm{C}\right]}\end{array}$ & $\begin{array}{c}d_{p} \\
{[\mu]}\end{array}$ & $\begin{array}{c}\bar{C} \\
\frac{g-\text { solid }}{\mathrm{cm}^{3}-\text { slurry }}\end{array}$ & {$\left[\begin{array}{c}\bar{u}_{\ell} \\
{[\mathrm{cm} / \mathrm{sec}]}\end{array}\right.$} & Key \\
\hline \multirow{9}{*}{6.6} & \multirow{9}{*}{201} & \multirow{9}{*}{$\begin{array}{c}19 \\
5 \\
23\end{array}$} & $63 \sim 88$ & 0.101 & 0.67 & 口 \\
\hline & & & \multirow{3}{*}{$88 \sim 105$} & \multirow{3}{*}{$\begin{array}{l}0.048 \\
1.202 \\
0.202\end{array}$} & 0.72 & $\nabla$ \\
\hline & & & & & 1.5 & $\nabla$ \\
\hline & & & & & 2.0 & $\nabla$ \\
\hline & & & \multirow{3}{*}{, $125 \sim 149$} & \multirow{3}{*}{$\begin{array}{l}0.075 \\
5 \\
0.119\end{array}$} & 0.80 & $\varnothing$ \\
\hline & & & & & 1.5 & $\phi$ \\
\hline & & & & & 2.0 & $\theta$ \\
\hline & & & \multirow{2}{*}{$149 \sim 177$} & \multirow{2}{*}{$\begin{array}{r}0.098 \\
\sim 0.108 \\
\end{array}$} & 1.5 & (1) \\
\hline & & & & & 2.2 & $\theta$ \\
\hline \multirow{11}{*}{12.2} & \multirow{11}{*}{196} & \multirow{11}{*}{$\begin{array}{c}15 \\
1 \\
20\end{array}$} & \multirow{4}{*}{$88 \sim 105$} & \multirow{4}{*}{$\begin{array}{l}0.066 \\
1 \\
0.116\end{array}$} & 0.50 & $\Delta$ \\
\hline & & & & & 0.86 & $\Delta$ \\
\hline & & & & & 1.25 & $\Delta$ \\
\hline & & & & & 2.07 & $\Delta$ \\
\hline & & & \multirow{3}{*}{$105 \sim 125$} & \multirow{3}{*}{$\begin{array}{l}0.051 \\
1 \\
0.142\end{array}$} & 0.74 & 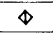 \\
\hline & & & & & 1.4 & $\ominus$ \\
\hline & & & & & 2.07 & $\diamond$ \\
\hline & & & \multirow{4}{*}{$125 \sim 149$} & \multirow{4}{*}{$\begin{array}{c}0.083 \\
1 \\
0.104\end{array}$} & 0.50 & 0 \\
\hline & & & & & 1.37 & $\theta$ \\
\hline & & & & & 1.5 & $\odot$ \\
\hline & & & & & 2.07 & $\otimes$ \\
\hline \multirow{8}{*}{21.4} & \multirow{8}{*}{405} & \multirow{8}{*}{$\begin{array}{c}11 \\
5 \\
19\end{array}$} & \multirow{2}{*}{$88 \sim 105$} & \multirow{2}{*}{$\begin{array}{r}0.096 \\
\sim 0.106 \\
\end{array}$} & 1.0 & $\triangleleft$ \\
\hline & & & & & 1.5 & 4 \\
\hline & & & \multirow{3}{*}{$125 \sim 149$} & \multirow{3}{*}{$\begin{array}{l}0.086 \\
1 \\
0.106\end{array}$} & 0.50 & $\varnothing$ \\
\hline & & & & & 1.0 & Q \\
\hline & & & & & 1.5 & $\phi$ \\
\hline & & & \multirow{3}{*}{ 149 177 } & \multirow{3}{*}{$\begin{array}{l}0.096 \\
0.109\end{array}$} & 0.50 & $\circ$ \\
\hline & & & & & 1.0 & 0 \\
\hline & & & & & 1.5 & - \\
\hline
\end{tabular}

were separated from the liquid, dried and weighed. The concentration of solid particles was expressed in grams of solid particles per $1 \mathrm{~cm}^{3}$ of slurry. The liquid mixing was measured by the method of delta response ${ }^{9}$, using a $\mathrm{KCl}$ solution as the tracer. The gas holdup was calculated from the height of the column and the liquid level containing solid particles measured by stopping the feed of gas and slurry simultaneously. The experimental conditions in continuous operations are summarized in Table 1.

\section{Analysis of Concentration Distribution of Solid Particles}

According to a sedimentation diffusion model in which the longitudinal movement of suspended solid particles is assumed to be caused by longitudinal dispersion and settling of solid particles and liquid flow, the concentration distribution of solid particles in the bubble column in steady-state, continuous operation is expressed by the equation ${ }^{7)}$

$$
\begin{aligned}
C & =\left(C_{0}+\frac{u_{l}}{v_{p}-u_{l}} C^{*}\right) \exp \left(-\frac{v_{p}-u_{l}}{E_{p}} z\right)-\frac{u_{l}}{v_{p}-u_{l}} C^{*} \\
& =\left(C_{L}+\frac{u_{l}}{v_{p}-u_{l}} C^{*}\right) \exp \left\{\frac{v_{p}-u_{l}}{E_{p}}(L-z)\right\}-\frac{u_{l}}{v_{p}-u_{l}} C^{*}
\end{aligned}
$$

By normalizing Eq.(1) with substitution of $X=C / C^{*}$, $X_{1}=C_{L} / C^{*}, Z=z / L, P_{p} B=v_{p} L / E_{p}$ and $P_{p l} B=u_{l} L / E_{p}$, the following equation is obtained:

$$
\begin{aligned}
X= & \left(X_{1}+\frac{P_{p l} B}{P_{p} B-P_{p l} B}\right) \exp \left\{\left(P_{p} B-P_{p l} B\right)(1-Z)\right\} \\
& -\frac{P_{p l} B}{P_{p} B-P_{p l} B}
\end{aligned}
$$

VOL. 5 NO. $2 \quad 1972$ 


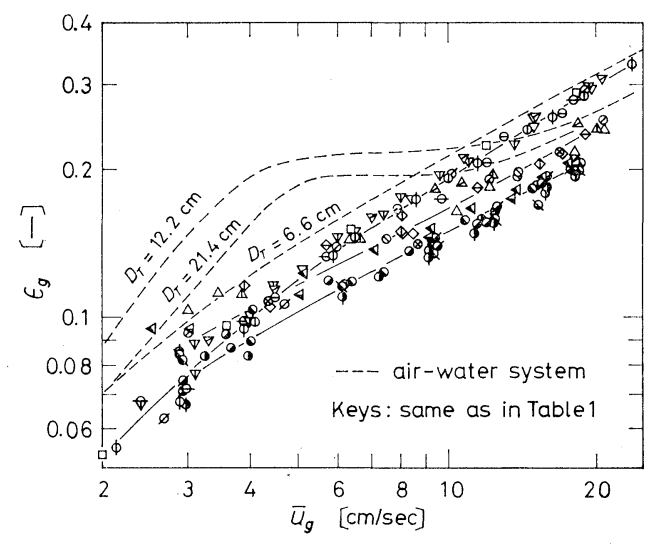

Fig. 2 Gas holdup in bubble columns containing suspended solid particles

In the case of batch operation with slurry, Eq.(1) reduces to the following equation, and $P_{p} B$ can be calculated from the observed concentration of solid particles and the axial height from the bottom of the column.

$$
C / C_{0}=\exp \left(-v_{p} z / E_{p}\right)=\exp \left(-P_{p} B \cdot Z\right)
$$

By substituting $X=X_{0.1}$ at $Z=0.1$ and $X=X_{0.76}$ at $Z=0.76$, respectively, into Eq.(2), the resulting equation is rearranged as follows:

$$
\begin{aligned}
& \frac{P_{p} B}{P_{p} B-P_{p l} B} \\
= & 1+\frac{X_{0.76} \exp \left\{\left(P_{p} B-P_{p l} B\right)(0.76-0.1)\right\}-X_{0.1}}{1-\exp \left\{\left(P_{p} B-P_{p l} B\right)(0.76-0.1)\right\}}
\end{aligned}
$$

Assuming that $E_{p}$ and $v_{p}$ are both independent of $u_{l}$ (this was verified from experimental results) $E_{p}$ and $v_{p}$ can be separately obtained in the following manner. By substituting $P_{p} B$ obtained from batch operation, and $X_{0.1}$ and $X_{0.76}$ obtained from continuous operation into Eq.(4), the value of $P_{p l} B$ which satisfies Eq.(4) can be obtained, and then $E_{p}$ can be obtained from $P_{p l} B, u_{l}$ and $L$. Furthermore, this $E_{p}, P_{p} B$ and $L$ give $v_{p}$. In the above calculations, the value of $P_{p} B$ in batch operation was corrected by using the correlation, $P_{p} B \propto v_{t}^{0,75}$, and Eq.(6) to a value under the liquid temperature and the average solid particle concentration in continuous operation, and the values of $X_{0.1}$ and $X_{0.76}$ used were obtained from the smoothing curve of the experimental values.

\section{Experimental Results and Discussion}

\section{1 Gas holdup}

Gas holdup data in bubble columns in which glass spheres were suspended are shown in Fig. 2. In the region of low gas velocity, the gas holdup of the airwater-glass sphere system is somewhat less than that of the air-water system; and the larger solid particles show a somewhat smaller gas holdup. According to visual observation, this is considered to be caused by the larger rising velocity of coalesced bubbles in the presence of solid particles. In the region of high gas velocity, where large coalesced bubbles rise frequently,

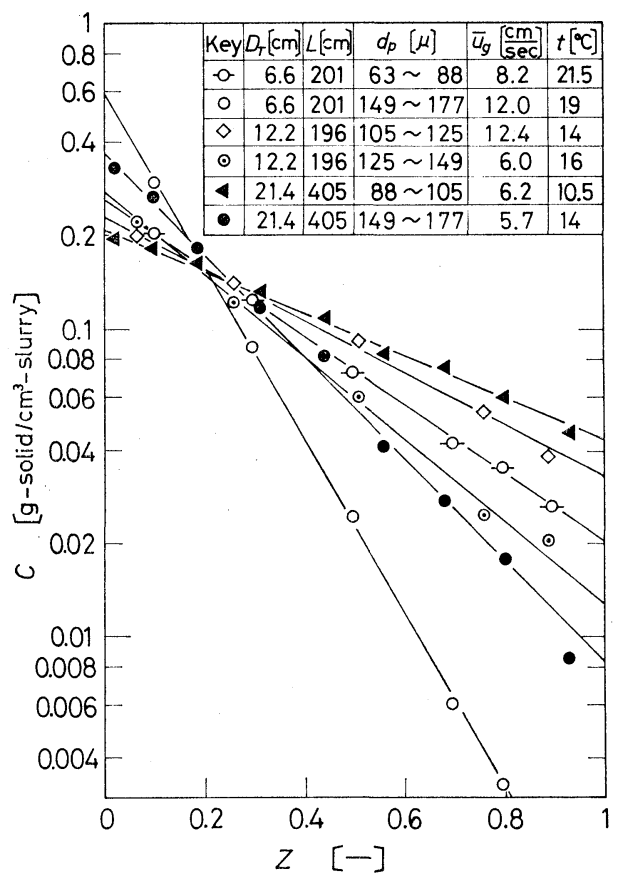

Fig. 3 Example data of concentration distribution of solid particles in batch operations

the effect of the concentration of solid particles on gas holdup becomes gradually smaller as gas velocity increases.

\subsection{Concentration distribution of solid particles in batch operations}

Example data of the concentration distribution of solid particles in batch operations with slurry are shown in Fig. 3. For an exact analysis of the concentration distribution of solid particles it is necessary to consider a voidage function at any local position, such as that used by Imafuku et al.5). However, because the logarithm of the solid particle concentration is almost proportional to the axial height from the bottom of the column in this experimental region, we made an approximation of the concentration distribution of solid particles in batch operations by Eq.(3).

In the case of solid particles, $88 \sim 105 \mu$ in diameter, $P_{p} B$ is proportional to the 0.75 th power of the terminal velocity of a single solid particle $v_{t}$ as the liquid temperature varies. This is shown in Fig. 4.

$$
P_{p} B \propto v_{t}{ }^{0.75}
$$

Fig. 5 shows the relationship between $P_{p} B$ and the volume fraction of liquid in slurry $\varphi_{l}\left(=1-\bar{C} / \rho_{p}\right)$. $P_{p} B$ decreases with a decrease in $\varphi_{l}$, or with an increase in $\bar{C}$ (this may be caused by a mutual interference between solid particles) and can be approximated by the equation

$$
P_{p} B=P_{p} B^{0} \varphi_{l}^{2,5}
$$

where $P_{p} B^{0}$ is the value of $P_{p} B$ extrapolated to $\varphi_{l}=1$.

Fig. 6 shows the effects of solid particle diameter, column diameter and gas velocity on the value of $P_{p} B$ corrected for temperature in batch operations. $P_{p} B$ decreases with an increase in $\bar{u}_{g}$ and $D_{T}$ and a decrease 


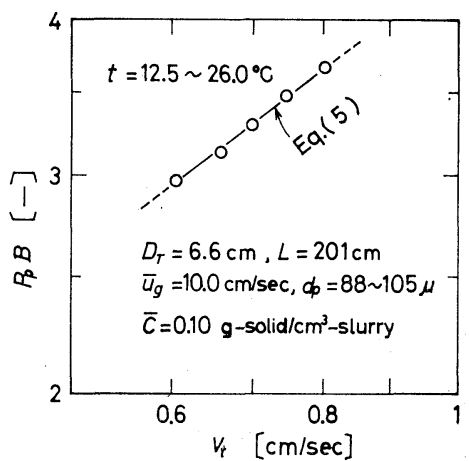

Fig. 4 Effect of $v_{t}$ on $P_{p} B$ in batch operations $\left(d_{p}=88 \sim 105 \mu\right)$

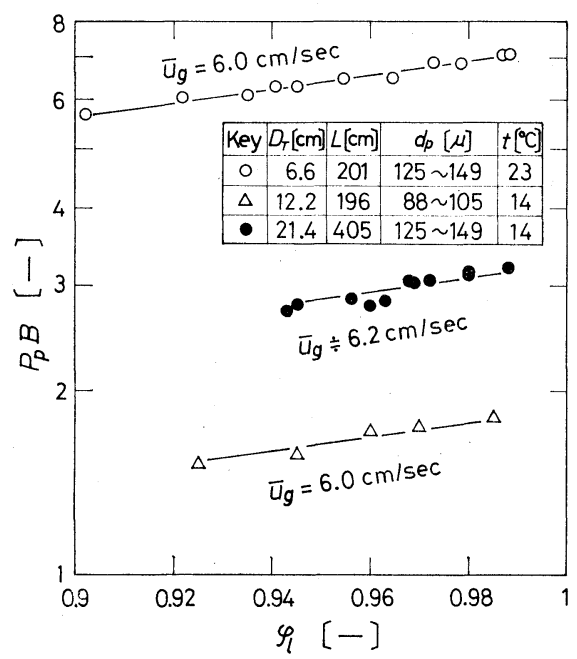

Fig. 5 Effect of $\varphi_{l}$ on $P_{p} B$ in batch operations

in $d_{p}$ (or a decrease in $v_{t}$ ). The interpolated value of $P_{p} B$ of solid particles of different sizes shown in Fig. 6 under the experimental conditions given in Fig. $4\left(D_{T}=6.6 \mathrm{~cm}, \bar{u}_{g}=10.0 \mathrm{~cm} / \mathrm{sec}\right.$ and $\bar{C}=0.1 \mathrm{~g}$ solid $/ \mathrm{cm}^{3}$-slurry), is on a straight line in Fig. 4 and satisfies Eq.(5).

3. 3 Goncentration distribution of solid particles in continuous operations

When the concentration distribution of solid particles in continuous operations is plotted, with the axial height from the bottom of the column as the abscissa, against the logarithm of solid particle concentration as the ordinate, curves depending upon the operating conditions are obtained as shown in Fig. 7. The solid lines in Fig. 7 are the concentration distribution curves of solid particles calculated as follows: Eq.(2) is transformed to have the term, $X_{0.1}$. The value of $P_{p l} B$ obtained by the method mentioned in section 2 , together with $P_{p} B$ and $X_{0.1}$, is substituted in the transformed equation, and the values of $X$ corresponding to $Z$ are calculated. The values of $C$ obtained by multiplying $X$ by $C^{*}$ and $Z$ give the concentration distribution curve of solid particles. All of the calculated curves fully satisfy the observed values; and, therefore, this sedimentation diffusion model

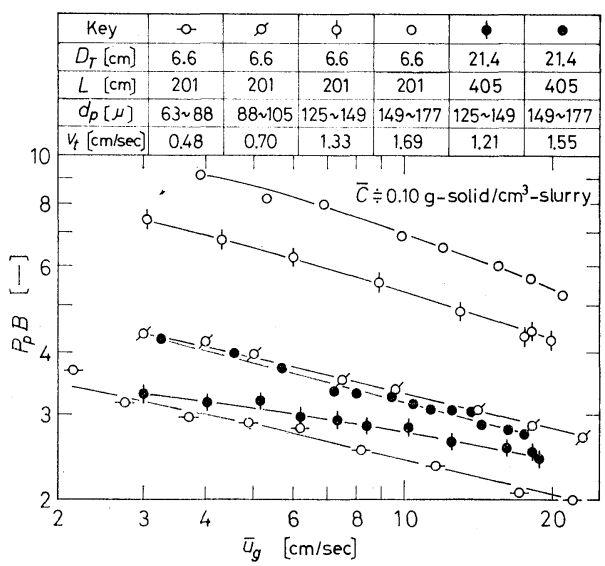

Fig. 6 Effects of particle diameter, column diameter and gas velocity on $P_{p} B$ in batch operations

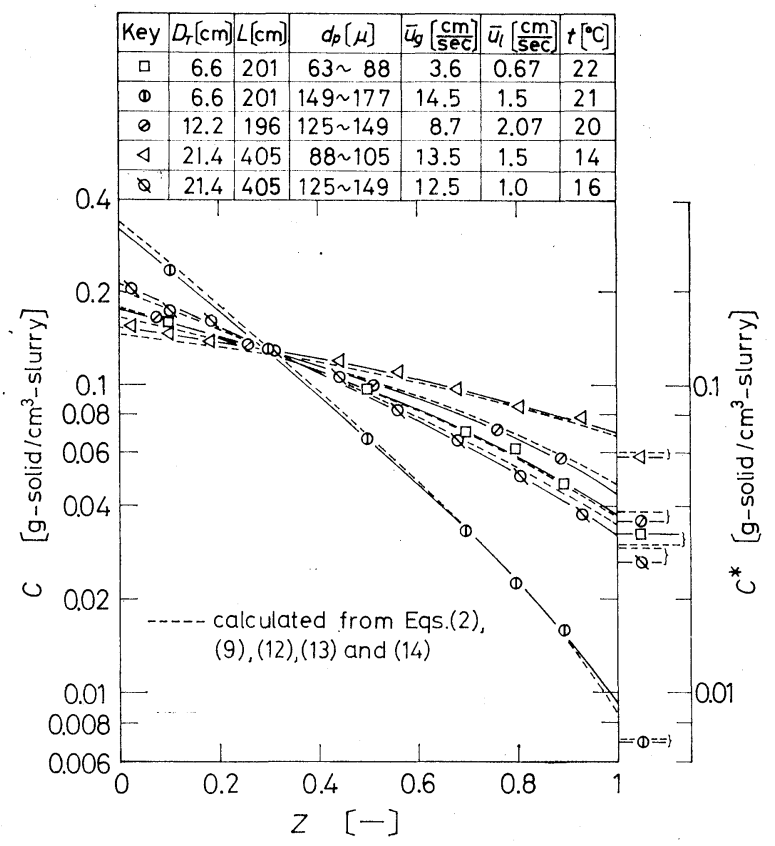

Fig. 7 Example data of concentration distribution of solid particles in continuous operations

is considered to be applicable to express the concentration distribution of solid particles in continuous operations.

3. 4 Longitudinal dispersion coefficient of suspended solid particles and liquid

The effects of particle diameter $d_{p}$, column diameter $D_{T}$, average solid particle concentration $\bar{C}$, slurry velocity $\bar{u}_{l}$ and gas velocity $\bar{u}_{g}$ on the longitudinal dispersion coefficient of solid particles $E_{p}$ are shown in Fig. 8. The effects of $d_{p}, D_{T}, \bar{C}, \bar{u}_{l}$ and $\bar{u}_{g}$ on the longitudinal dispersion coefficient of liquid in slurry $E_{s l}$ are shown in Fig. 9. In Fig. 8 the data of $E_{p}$ obtained by Imafuku et al. ${ }^{5)}$ are also plotted, and the data of $E_{s l}$ of this experiment are shown by broken lines. In Fig. 9 the data of $E_{l}{ }^{6)}$ in the air-water system are shown by broken lines. $E_{p}, E_{s l}$ and $E_{l}$ 


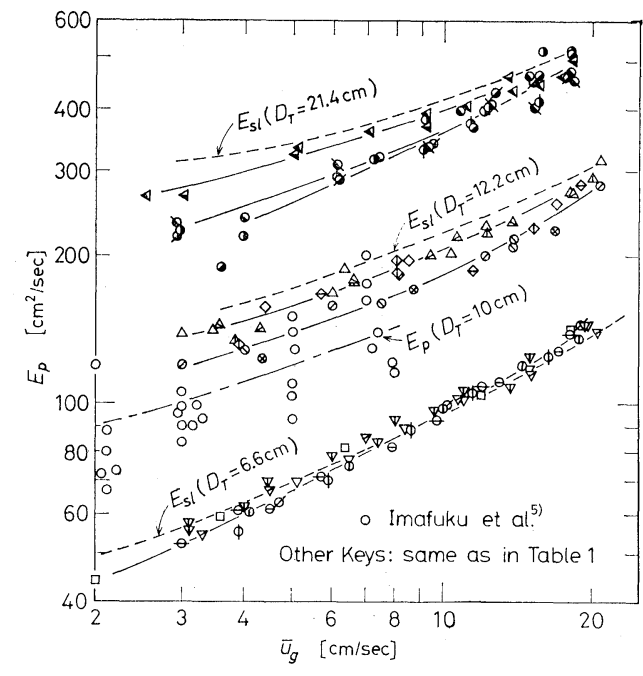

Fig. 8 Effects of particle diameter, column diameter, average solid particle concentration, slurry velocity and gas velocity on longitudinal dispersion coefficient of solid particles

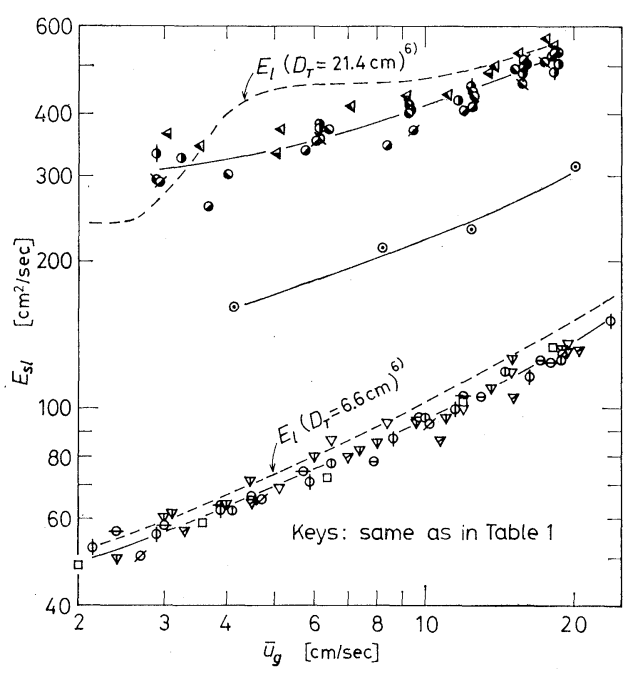

Fig. 9 Effects of particle diameter, column diameter, average solid particle concentration, slurry velocity and gas velocity on longitudinal dispersion coefficient of liquid in slurry

increase with an increase in $\bar{u}_{g}$ and are proportional to the $1 \sim 1.5$ th power of $D_{T} . \quad E_{p}$ and $E_{s l}$ are independent of $\bar{u}_{l}$ as is the case of $E_{l}$; and $E_{p}$ is almost independent of the average solid particle concentration. In the case of large $d_{p}$ (or large $v_{t}$ ), at low $\bar{u}_{g}, E_{p}$ is less than $E_{s l}$; but as $\bar{u}_{g}$ increases, $E_{p}$ gradually approaches $E_{s l}$. In the case of small $d_{p}$ (or small $v_{t}$ ), $E_{p}$ is nearly equal to $E_{s l}$, including the range of low $\bar{u}_{g}$. When the column diameter becomes as small as $6.6 \mathrm{~cm}$, the effect of $d_{p}$ on $E_{p}$ becomes very small.

In the same manner as the arrangement concerning $E_{l}$ in a previous paper6), Peclet number $(P e)_{p}$ including $E_{p}$, and $(P e)_{s l}$ including $E_{s l}$ are plotted as the ordinate against Froude number $F r$ as the abscissa in Fig. 10 and Fig. 11, respectively. The relationship between $(P e)_{s l}$ and $F r$ and the relationship

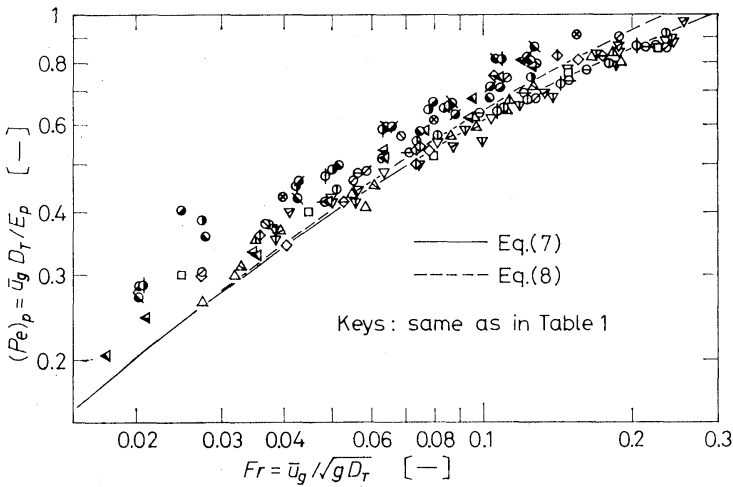

Fig. 10 Relationship between $(\mathrm{Pe})_{p}$ and $\mathrm{Fr}$

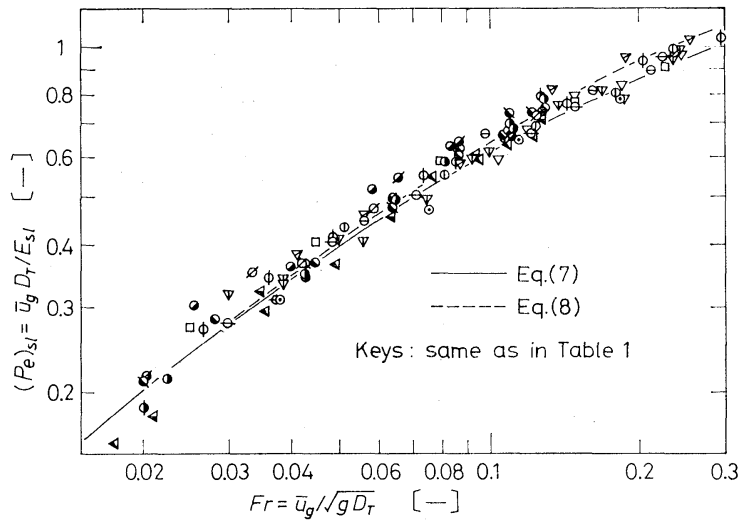

Fig. 11 Relationship between $(\mathrm{Pe})_{s l}$ and $\mathrm{Fr}$

between $(P e)_{p}$ in the case of small $d_{p}$ and $F r$ are shown approximately by the solid line and are expressed by the following equation:

$$
(P e)_{s l}=(P e)_{p}=13 F r /\left(1+8 F r^{0,85}\right)
$$

The broken lines in Fig. 10 and Fig. 11 show the values calculated from the following empirical equation, which was reported previously concerning $E_{l}$ for the gas-liquid system in a bubble column with diameter larger than $12.2 \mathrm{~cm}$, using a perforated plate of hole diameter more than $0.2 \mathrm{~cm}$ or a nozzle as a gas distributor $^{6}$ :

$$
\bar{u}_{g} D_{T} / E_{l}=13 F r /\left(1+6.5 F r^{0,8}\right)
$$

In Fig. 10, the value of $(P e)_{p}$ of large $d_{p}$ is larger than that of small $d_{p}$ at low $F r$, but gradually approaches that of small $d_{p}$ as $F r$ increases. This tendency is pronounced for the $21.4 \mathrm{~cm}$ column. Led by the examination of the correlation between $(P e)_{p}$ and Reynolds number $\operatorname{Re}_{p}\left(=\bar{d}_{p} v_{t} / \nu\right)$ at $F r=0.02$ and $F r=0.05$ in this column, the relation is expressed by $(P e)_{p}=(P e)_{p}^{0}\left(1+a R e_{p}\right)$, where $(P e)_{p}^{0}$ is the value of $(P e)_{p}$ calculated from Eq.(7). The relation between $a$ and $\mathrm{Fr}$ has been approximated by $a=0.009 F r^{-0.8}$. Assuming that these relations are applicable to the 12.2 and $6.6 \mathrm{~cm}$ columns, all data are plotted with $(P e)_{p} /$ $\left(1+0.009 R e_{p} F r^{-0.8}\right)$ as the ordinate and $F r$ as the abscissa, as shown in Fig. 12, and then the following 


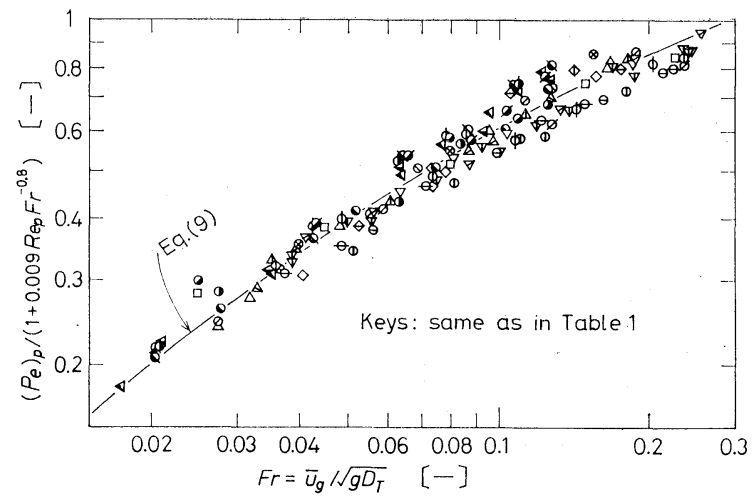

Fig. 12 Relationship between $(\mathrm{Pe})_{p} /\left(1+0.009 \operatorname{Re}_{p} \mathrm{Fr}^{-0.8}\right)$ and $\mathrm{Fr}$

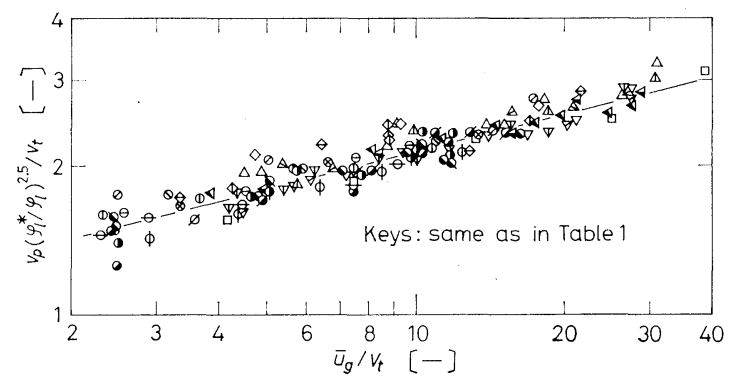

Fig. 13 Relationship between $v_{p}\left(\varphi_{l}^{*} / \varphi_{l}\right)^{2.5} / v_{t}$ and $\overline{\boldsymbol{v}}_{g} / \mathbf{v}_{t}$

empirical equation can be obtained:

$$
(P e)_{p}=13 F r\left(1+0.009 \operatorname{Re}_{p} F r^{-0.8}\right) /\left(1+8 F r^{0.85}\right)
$$

\section{5 Mean settling velocity of solid particles}

As $E_{p}$ is almost independent of the average solid particle concentration $\bar{C}$ in the range of $\bar{C}=0.048 \sim$ $0.20 \mathrm{~g}$-solid $/ \mathrm{cm}^{3}$-slurry, the following equation between $v_{p}$ and $\varphi_{l}$ is obtained from Eq.(6):

$$
v_{p}=v_{p}^{0} \varphi_{l}^{2.5}
$$

where $v_{p}^{0}$ is the value of $v_{p}$ extrapolated to $\varphi_{l}=1$. As most of these experiments were carried out under the condition of $\bar{C}=0.1 \mathrm{~g}$-solid $/ \mathrm{cm}^{3}$-slurry, denoting the value of $\varphi_{l}$ at $\bar{C}=0.1 \mathrm{~g}$-solid $/ \mathrm{cm}^{3}$-slurry by $\varphi_{l}^{*}$, the mean settling velocity of solid particles corrected to the value at $\bar{C}=0.1$ is expressed as $v_{p}\left(\varphi_{l}^{*} / \varphi_{l}\right)^{2.5}$. The ratio of $v_{p}\left(\varphi_{l}^{*} / \varphi_{l}\right)^{2.5}$ to the terminal velocity of a single particle $v_{t}$, namely $v_{p}\left(\varphi_{l}^{*} / \varphi_{l}\right)^{2.5} / v_{t}$, is plotted as the ordinate against $\bar{u}_{g} / v_{t}$ as the abscissa as in Fig. 13. $v_{p}$ is almost independent of $D_{T}$ and $\bar{u}_{l}$ and can be approximated by the following equation:

$$
v_{p}=1.20 v_{t}\left(\bar{u}_{g} / v_{t}\right)^{0.25}\left(\varphi_{l} / \varphi_{l}^{*}\right)^{2.5}
$$

where $\varphi_{l}^{*}=0.96$. Substituting this value into Eq.(11), it reduces to the equation

$$
v_{p}=1.33 v_{t}\left(\bar{u}_{g} / v_{t}\right)^{0.25} \varphi_{l}^{2.5}
$$

3. 6 The ratio of the solid particle concentration in slurry at the top of the column to that in effluent (or feed) slurry

In the case of cocurrent flow, the solid particle concentration in the effluent (or feed) slurry $C^{*}$ is less than that in slurry at $z=L, C_{L}$, as shown in Fig. 7 .

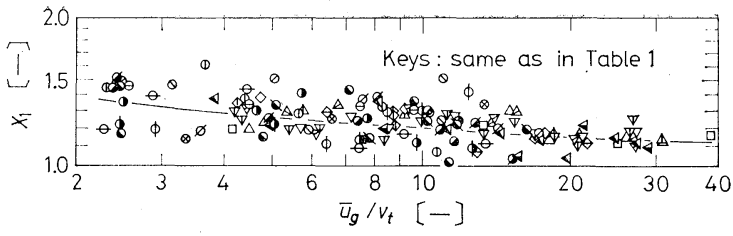

Fig. 14 Relationship between $X_{1}$ and $\bar{v}_{g} / v_{t}$

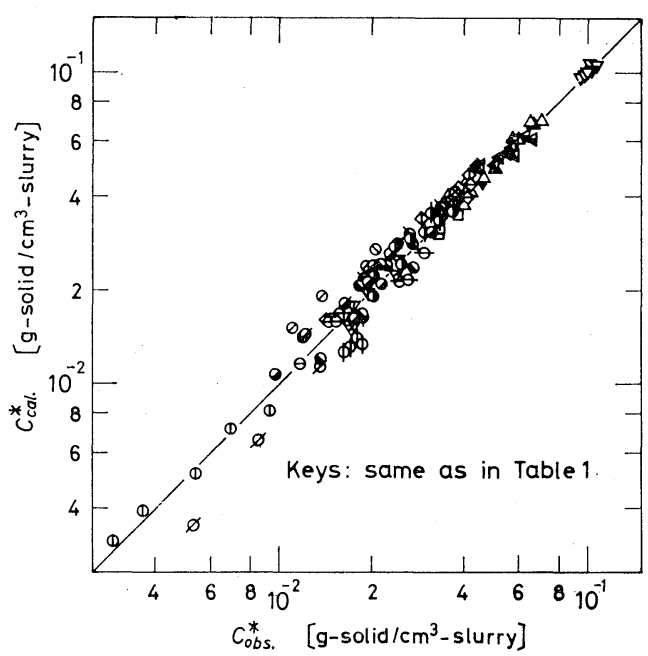

Fig. 15 Comparison of calculated and observed effluent (or feed) concentration of solid particles

Suganuma et al. ${ }^{8)}$ recognized this relationship qualitatively, but they did not present the empirical equation. In this experiment, $X_{1}=C_{L} / C^{*}$ is almost independent of $D_{T}, \bar{C}$ and $\bar{u}_{l}$, but it decreases with an increase in $\bar{u}_{g}$ and with a decrease in $v_{t}$. Then $X_{1}$ was plotted as the ordinate against $\left(\bar{u}_{g} / v_{t}\right)$ as the abscissa in Fig. 14, and is expressed as a function of $\left(\bar{u}_{g} / v_{t}\right)$. As $X_{1}$ should reduce to unity when $\bar{u}_{g}$ is infinity and $v_{t}$ is infinitesimal, the following empirical equation was obtained:

$$
X_{1}=1+0.5\left(\bar{u}_{g} / v_{t}\right)^{-0.4}
$$

\section{7 Comparison of observed values with calculated} values

The concentration distribution of solid particles and the concentration of solid particles in effluent (or feed) slurry can be calculated from empirical Eqs.(9), (12) and (13), the basic Eq.(2) and the following Eq.(14).

$$
\begin{aligned}
\bar{X} & =\left(X_{1}-\frac{P_{p l} B}{P_{p} B-P_{p l} B}\right)\left(\frac{\exp \left(P_{p} B-P_{p l} B\right)-1}{P_{p} B-P_{p l} B}\right) \\
& -\frac{P_{p l} B}{P_{p} B-P_{p l} B}
\end{aligned}
$$

The broken lines in Fig. 7 show the values calculated from the above equations and agree satisfactorily with the observed values. The largest difference between observed and calculated concentration of solid particles seems to occur in the concentration of effluent slurry. This comparison of calculated and obserbed effluent concentration of solid particles is shown in Fig. 15. The calculated values agree with the observed ones within $\pm 20 \%$.

VOL. 5 NO. $2 \quad 1972$ 


\section{Conclusion}

The longitudinal concentration distribution of solid particles and liquid mixing have been studied. The concentration distribution of solid particles was analyzed by using a sedimentation diffusion model.

Empirical equations (9), (12) and (13) were obtained for the longitudinal dispersion coefficient of solid particles, the mean settling velocity of solid particles and the ratio of the solid particle concentration in slurry at the top of the column to that in effluent slurry, respectively. The longitudinal dispersion coefficient of liquid in slurry was correlated by Eq.(7). Furthermore, the values of solid particles concentration calculated from Eqs.(9), (12) and (13) and Eqs.(2) and (14) agree with the observed ones within $\pm 20 \%$.

\section{Acknowledgement}

The authors wish to thank Mr. Tokihiro Kago (Department of Applied Chemisty, Kyushu University) and $\mathrm{Mr}$. Hironori Haneda (Government Research Institute for Pollution and Resources) for their technical assistance. For this study's calculations, OKITAC-5090H computer of Kyushu University Computation Center was used.

\section{Nomenclature}

$C=$ concentration of solid particles in slurry

[g-solid $/ \mathrm{cm}^{3}$-slurry]

$C_{0}=$ concentration of solid particles in slurry at $z=0$

$C_{L} \quad\left[\mathrm{~g}\right.$-solid $/ \mathrm{cm}^{3}$-slurry]

$C_{L}=$ concentration of solid particles in slurry at $z=L$ [g-solid $/ \mathrm{cm}^{3}$-slurry]

$C^{*} \quad=$ concentration of solid particles in feed or effluent

$\bar{C} \quad\left[\mathrm{~g}\right.$-solid $/ \mathrm{cm}^{3}$-slurry]

$\bar{C}=$ average concentration of solid particles in slurry

$d_{p} \quad=$ diameter of a solid particle $\quad\left[\right.$ 'solid $/ \mathrm{cm}^{3}$-slurry $]$

$\bar{d}_{p}=$ mean diameter of solid particles $\quad[\mathrm{cm}]$

$D_{T}=$ diameter of column $\quad[\mathrm{cm}]$

$E_{l} \quad=$ longitudinal dispersion coefficient of liquid based on actual mean liquid velocity for gas-liquid system $\left[\mathrm{cm}^{2} / \mathrm{sec}\right]$

$E_{p} \quad=$ longitudinal dispersion coefficient of solid particles based on actual mean slurry velocity

$\left[\mathrm{cm}^{2} / \mathrm{sec}\right]$

$E_{s l} \quad=$ longitudinal dispersion coefficient of liquid in slurry based on actual mean slurry velocity $\left[\mathrm{cm}^{2} / \mathrm{sec}\right]$

Fr $=\bar{u}_{g} / \sqrt{g D_{T}}$, Froude number

$g \quad=$ gravitational acceleration $\quad\left[\mathrm{cm} / \mathrm{sec}^{2}\right]$
$L \quad=$ height of column

$(P e)_{p}=\bar{u}_{g} D_{T} / E_{p}$, Peclet number based on $E_{p}$

$(P e)_{s l}=\bar{u}_{g} D_{T} / E_{s l}$, Peclet number based on $E_{s l}$

$P_{p} B=v_{p} L / E_{p}$

$P_{p} B^{0}=$ value of $P_{p} B$ extrapolated to $\varphi_{l}=1$

$P_{p l} B=u_{l} L / E_{p}$

$\operatorname{Re}_{p}=\bar{d}_{p} v_{t} / \nu$, Reynolds number

$t=$ temperature of slurry

$\bar{u}_{g} \quad=$ superficial velocity of gas based on empty column

$\bar{u}_{l} \quad=$ superficial velocity of slurry based on empty column [cm/sec]

$u_{l}=\bar{u}_{l} /\left(1-\epsilon_{g}\right)$, actual mean velocity of slurry

$v_{p} \quad=$ mean settling velocity of solid particles $[\mathrm{cm} / \mathrm{sec}]$

$[\mathrm{cm} / \mathrm{sec}]$

$v_{p}^{0}=$ value of $v_{p}$ extrapolated to $\varphi_{l}=1 \quad[\mathrm{~cm} / \mathrm{sec}]$

$v_{t}=$ terminal velocity of a single solid particle in stagnant liquid $\quad[\mathrm{cm} / \mathrm{sec}]$

$X=C / C^{*}$, normalized concentration of solid particles

$\bar{X}=\bar{C} / C^{*}$, normalized average concentration of solid particles

$X_{0.1}=$ value of $X$ at $Z=0.1$

$X_{0.76}=$ value of $X$ at $Z=0.76$

$X_{1}=C_{L} / C^{*}$, value of $X$ at $Z=1$

$z \quad=$ axial height from the bottom of column $[\mathrm{cm}]$

$Z \quad=z / L$, normalized axial height from the bottom of column

$\epsilon_{g} \quad=$ gas holdup

$\nu \quad=$ kinematic viscosity of liquid

volume fraction of liquid in $\left[\mathrm{g} / \mathrm{cm}^{3}\right]$

particle $=1-($ volume fraction of solid particles in slurry)

$\varphi_{l}^{*} \quad=$ value of $\varphi_{l}$ at $\bar{C}=0.1$

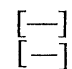

\section{Literature Cited}

1) Aoyama, Y., K. Ogushi, K. Koide and H. Kubota: J. Chem. Eng. Japan, 1, 158 (1968)

2) Cova, D. R.: Ind. Eng. Chem., Process Design and Develop., 5, 20 (1966)

3) Farkas, E. J. and P. F. Leblond: Can. J. Chem. Eng., 47, 215 (1969)

4) Goto, Y., T. Okamoto and T. Terahata: Preprint of the 34th Annual Meeting of the Soc. of Chem. Engrs., Japan, No. C 101 (1969)

5) Imafuku, K., T. Wang, K. Koide and H. Kubota: J. Chem. Eng. Japan, 1, 153 (1968)

6) Kato, Y. and A. Nishiwaki: Kagaku Kōgaku, 35, 912 (1971)

7) Suganuma, T. and T. Yamanishi: ibid., 30, 1136 (1966)

8) Suganuma, T. and T. Yamanishi: ibid., 31, 1006 (1967)

9) Yagi, S. and T. Miyauchi: ibid., 17, 382 (1953) 